\title{
Influence Analysis of Current Limiting Reactor on Pole-to-Pole Short Circuit Fault in DC Distribution System
}

\author{
Zhenyu Wang ${ }^{1,2^{*}}$, Shouxiang Wang ${ }^{1,2}$, Qi Liu ${ }^{1,2}$, Chunyu Zhang ${ }^{1,2}$, Qianyu Zhao ${ }^{1,2}$ and Hao $\mathrm{Mu}^{3}$ \\ ${ }^{1}$ Key Laboratory of Smart Grid of Ministry of Education, Tianjin University, Tianjin 300072, China \\ ${ }^{2}$ Key Laboratory of Power System Simulation and Control, Tianjin University, Tianjin 300072, China \\ ${ }^{3}$ State Grid Tianjin Electric Power Company, Hebei District, Tianjin, 300010, China
}

\begin{abstract}
With the development of power electronic technology, flexible DC distribution system has gradually become a research hotspot. Pole-to-pole short circuit fault is the most serious fault type in DC distribution system. When pole-to-pole short circuit fault occurs in DC side, it will produce a large fault current, which will cause serious harm to DC distribution system. Therefore, it is urgent to install current limiting reactor to limit fault over-current. Aiming at the DC distribution system based on half bridge MMC, this paper analyses the fault mechanism and fault characteristics of pole-to-pole short circuit fault, studies the current limiting effect of the installation position and capacity of current limiting reactor on fault current, and carries out simulation verification in PSCAD / EMTDC platform. The analysis and simulation results show that installing a current limiting reactor at the outlet of the DC side can reduce the peak value of capacitor discharge current, and installing a current limiting reactor at the outlet of the AC side can reduce the overall amplitude of fault current.
\end{abstract}

\section{Introduction}

In recent years, flexible DC distribution network has gradually become the research focus of domestic and foreign scholars ${ }^{[1]}$. Compared with the traditional AC distribution network, flexible DC distribution network has the advantages of large power supply capacity and good power quality, which has important research value $^{[2]}$.

The fault types of flexible DC system are mainly divided into pole-to-pole short circuit fault, single-pole grounding faults and disconnection faults ${ }^{[3]}$. Among them, pole-to-pole short circuit fault are the most serious fault types, which have serious harm to the DC distribution system ${ }^{[4]}$. After a fault occurs, the fault current will rise to several tens of times the normal current within a few milliseconds ${ }^{[5]}$, which puts forward high requirements on the action speed of the protection scheme. Therefore, it is of great significance to study the current limiting measures to reduce the fault over-current and ensure the safe and reliable isolation of DC side fault.

In reference [6], the transient process of pole-to-pole short circuit fault is divided into pre blocking stage and post blocking stage. A protection strategy is proposed to limit the fault current amplitude and rise rate by increasing the bridge arm reactance. An improved scheme of double thyristor method is proposed in reference [7]. This method overcomes the shortcomings of the double thyristor method in isolation speed, protection dead zone and AC side over-current, and improves the speed and range of fault isolation. In reference [8], an over-current suppression strategy based on virtual impedance is proposed. The characteristics of actual circuit elements are mapped into the control system through double closed-loop vector control strategy to achieve the purpose of suppressing fault overcurrent.

At present, there are few studies on the effect of the installation position and capacity of the current limiting device on the current limiting effect. This paper analyses the fault mechanism and characteristics of pole-to-pole short circuit in the DC distribution system based on half bridge MMC. The influence of current limiting reactor installation position and capacity on current limiting effect before and after converter station blocking is studied, which provides theoretical basis for pole-to-pole short circuit fault isolation and protection configuration of DC distribution system.

\section{Fault Mechanism of Pole-to-Pole Short Circuit in DC Distribution System}

Figure 1 shows the topology of a typical two terminal flexible DC distribution network. 


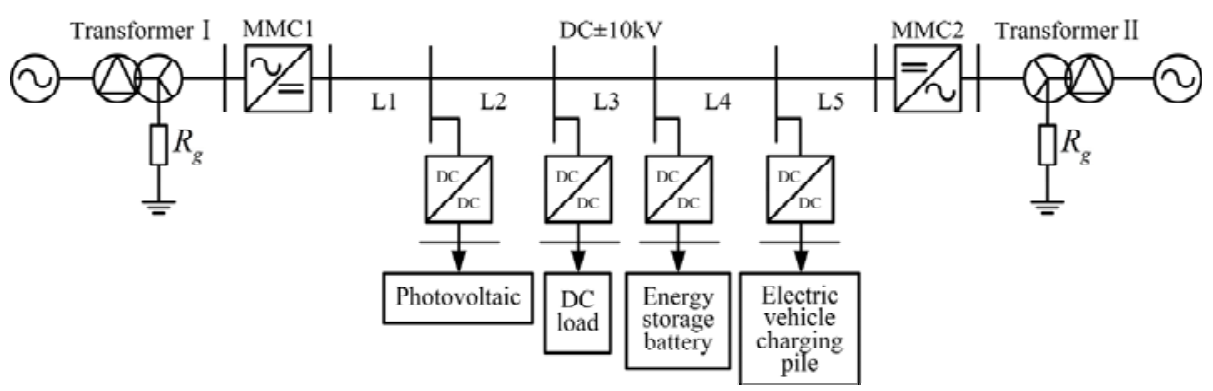

Figure 1 Structure diagram of flexible double end

The transient process after DC pole-to-pole short circuit fault can be divided into three stages: the stage before converter station blocking, the initial stage after converter station blocking, and the steady-state operation stage of uncontrolled rectifier. However, when the converter station can quickly block after fault, the overcurrent can be effectively limited, and the characteristics of the initial stage after blocking will no longer exist, but directly transition into the steady-state operation stage of uncontrolled rectifier $^{[9]}$. Therefore, this paper divides the post fault transient stage into two stages: before converter station blocking and after converter station blocking. The converter station will be locked within $5 \mathrm{~ms}$ after the fault. The inter pole short circuit fault current path is shown in Figure 2. Before blocking, the fault current in the circuit mainly includes the discharge current of the bridge arm capacitor through IGBT and the short circuit current fed into the DC side through the bridge arm diode on the AC side, as shown in the blue circuit in the figure. After blocking, the fault current in the circuit is mainly the feed current on the $\mathrm{AC}$ side, as shown in the red circuit in the figure.

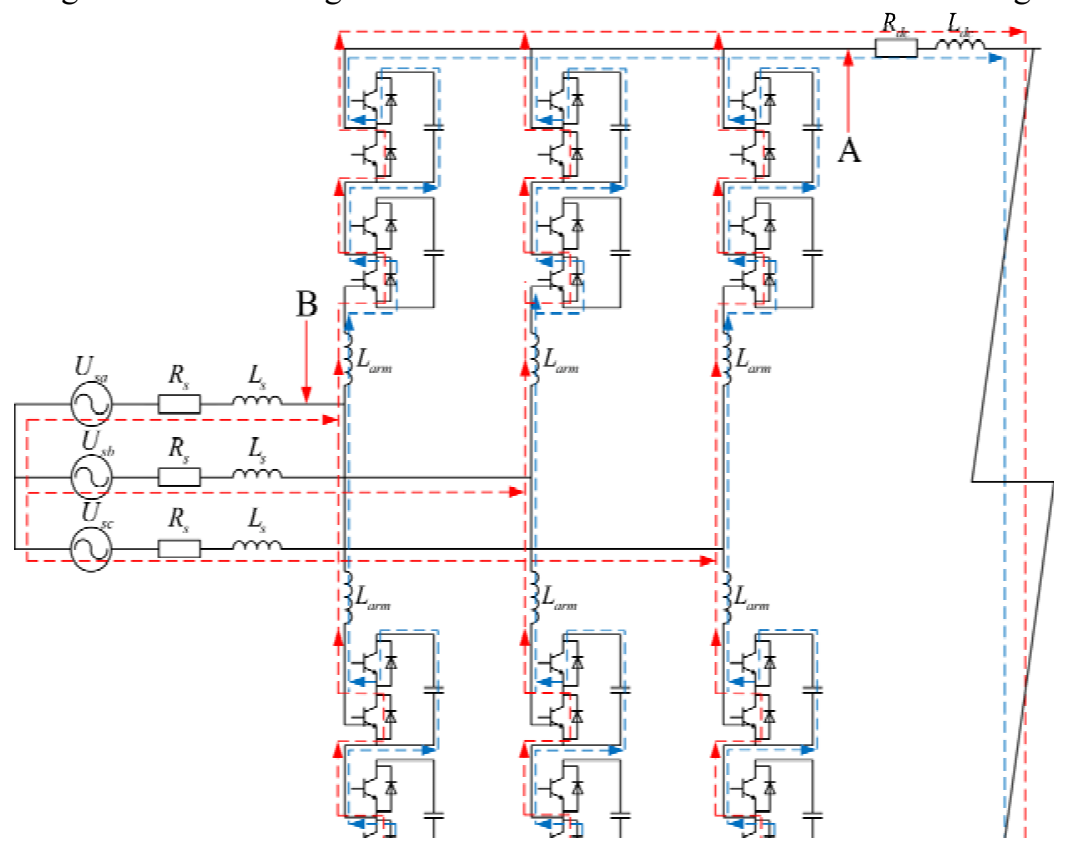

Figure 2 Fault current path after pole-to-pole fault

In the figure, $U_{s a}, U_{s b}$ and $U_{s c}$ are the three-phase voltages of $\mathrm{AC}$ side $\mathrm{A}, \mathrm{B}$, and $\mathrm{C}$ respectively; $L_{\text {arm }}$ are MMC bridge arm inductors; $L_{s}$ and $R_{s}$ are AC side inductors and resistors; $L_{d c}$ and $R_{d c}$ are DC side inductors and resistors.

The capacitor discharge circuit shown in the blue path can be further equivalent to the circuit shown in Figure 3 .

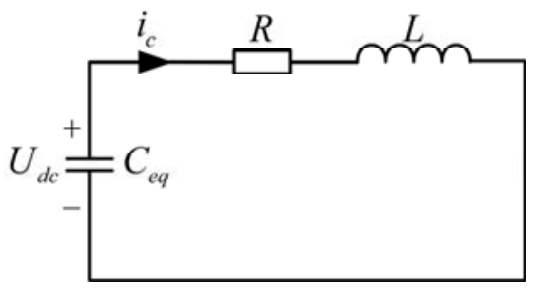

Figure 3 Capacitor discharge equivalent circuit

Where, $C_{e q}=6 C_{0} / N, C_{0}$ is the capacitance value of a single sub module, $\mathrm{N}$ is the number of one phase bridge arm modules, $L=2 L_{d c}+2 L_{a r m} / 3, R=2 R_{d c}$. Since the loop resistance is far less than $2 \sqrt{L / C}$, the loop is a second-order underdamping loop. The calculation 
formula of discharge current of capacitor is given in reference [10]:

$$
i_{c}(t)=e^{-\frac{t}{\tau}}\left[\sqrt{\frac{C}{L} U_{d c}^{2}+I_{0}^{2}} \sin (\omega t+\beta)\right]
$$

Where:

$$
\left\{\begin{array}{c}
\tau=\frac{2 L}{R} \\
\omega=\sqrt{\frac{1}{L C}-\left(\frac{R}{2 L}\right)^{2}} \\
\beta=\arctan \left(\frac{I_{0}}{U_{d c}} \sqrt{\frac{L}{C}}\right)
\end{array}\right.
$$

The AC feed in circuit shown in the red path in Figure 2 can be regarded as a three-phase uncontrollable rectifier bridge, which is further equivalent to the circuit shown in Figure 4.

$$
\begin{aligned}
& I_{2}=\frac{1}{\frac{\pi}{3 \omega^{\prime}}} \int_{\frac{\phi-\phi^{\prime}}{\omega^{\prime}}}^{\frac{\phi-\phi_{0}}{\omega^{\prime}}+\frac{2 \pi}{3 \omega^{\prime}}} \frac{U_{m}}{3 \omega^{\prime}} \frac{U_{m}}{\sqrt{R_{s}^{2}+\omega^{\prime 2}\left(L_{s}+L_{a r m}\right.}} \\
& \text { Analysis of Installation } \\
& \text { Current Limiting Reactor }
\end{aligned}
$$

\subsection{Analysis of The Influence of Reactor Current Limiting Before Converter Station Blocking}

(1) Adding current limiting reactor on DC side Install a current limiting reactor at DC outlet $\mathrm{A}$ in Figure 2. It can be seen from equations (1), (2), (3) and (4) that adding a current limiting reactor on the DC side can effectively reduce the amplitude of capacitor discharge current, and has no obvious effect on the amplitude of $\mathrm{AC}$ feed in current. However, due to the effect of inductance hindering the change of current, the fluctuation of fault current will be reduced to a certain extent.

(2) Adding current limiting reactor on AC side

In Figure 2, a current limiting reactor is added to the three-phase line at $\mathrm{AC}$ outlet $\mathrm{B}$. It can be seen from equations (3) and (4) that adding a current limiting reactor on the $\mathrm{AC}$ side will increase the inductance on the $\mathrm{AC}$ side, reduce the amplitude of fault current on the AC side, and then reduce the amplitude of fault current fed into the DC side by the three-phase bridge arm on the AC side.

\subsection{Influence Analysis of Reactor Current Limiting After Converter Station Blocking}

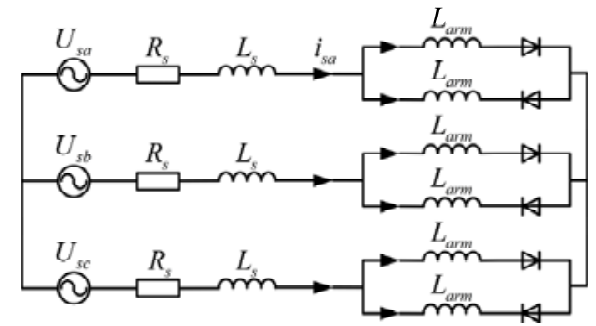

Figure 4 Equivalent circuit of three-phase uncontrolled rectifier bridge

Set AC a phase voltage of $U_{s a}=U_{m} \sin \left(\omega^{\prime} t+\phi_{0}\right)$, so the fault phase current on AC side can be expressed as:

$$
i_{s a}=\frac{U_{m}}{\sqrt{R_{s}^{2}+\omega^{\prime 2}\left(L_{s}+L_{a r m} / 2\right)^{2}}} \sin \left(\omega^{\prime} t+\phi_{0}-\phi\right)
$$

Where, $\phi$ is the phase angle of AC system; $\phi_{0}$ is the phase angle of AC system at fault time.

Due to the unidirectional conductivity of the diode, the A-phase bridge arm current is the positive half period of the fault phase current. Therefore, the current fed from $\mathrm{AC}$ side to DC side can be expressed as the superposition of $\mathrm{A}, \mathrm{B}$ and $\mathrm{C}$ three-phase bridge arm current, that is, the superposition of the positive half period of the threephase fault current. The average value is:

$$
\sin \left(\omega^{\prime} t+\phi_{0}-\phi\right) d t=\frac{3 U_{m}}{\pi \sqrt{R_{s}^{2}+\omega^{\prime 2}\left(L_{s}+L_{a r m} / 2\right)^{2}}}
$$

In the steady-state operation stage of uncontrolled rectifier after converter station blocking, the DC side fault current only includes the AC side feed current, so the installation of current limiting reactor on the DC side has no obvious effect on the fault current amplitude, but the steady-state current fluctuation will be reduced due to the inductance hindering the current change.

(2) Adding current limiting reactor on AC side

It can be seen from equations (3) and (4) that adding a current limiting reactor on the AC side can effectively reduce the amplitude of fault phase current on the AC side, and then reduce the amplitude of fault current fed into the DC side through the three-phase bridge arm on the AC side.

\section{Simulation Analysis}

According to the typical two terminal flexible DC distribution network shown in Figure 1, simulation analysis is carried out based on the PSCAD/EMTDC platform. Among them, the rated voltage of DC side is $\pm 10 \mathrm{kV}$, the capacitance of converter valve is $20000 \mathrm{uF}$, the inductance of converter valve is $0.02 \mathrm{H}$, the unit resistance and unit inductance of DC line are $0.2 \Omega / \mathrm{km}$ and $0.1 \mathrm{mH} / \mathrm{km}$ respectively, the line length is $10 \mathrm{~km}$, and the pole-to-pole short circuit fault is set $1 \mathrm{~km}$ away from MMC1 converter valve. When the fault is set to $2 \mathrm{~s}$, the duration is $0.5 \mathrm{~s}$, and the converter is locked $5 \mathrm{~ms}$ after the fault.

(1) Adding current limiting reactor on DC side 


\subsection{Simulation Analysis of Current Limiting Installation of Reactor on DC Side}

Install $0 \mathrm{mH}, 30 \mathrm{mH}$ and $60 \mathrm{mH}$ current-limiting reactors at the outlet of the DC side respectively. The current of the DC side line after the fault is shown in Figure 5.

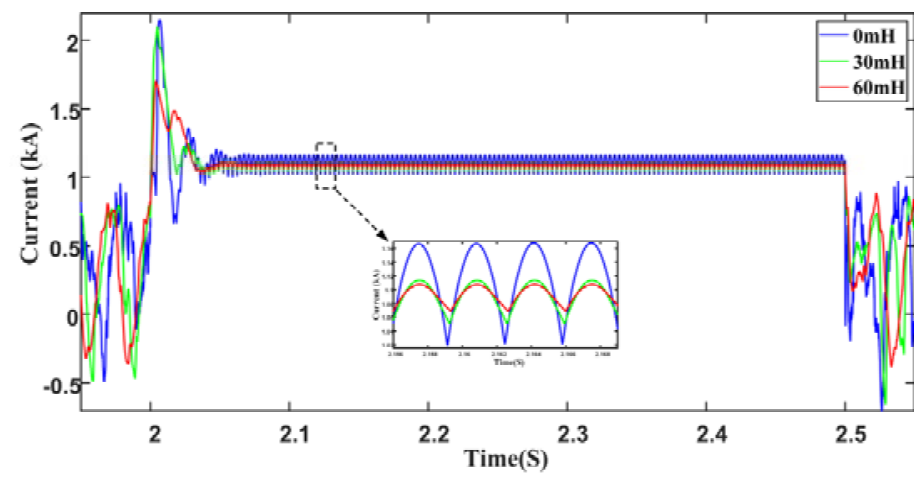

Figure 5 Fault current waveforms with current-limiting reactor at DC side

It can be seen that with the increase of reactance value of current limiting reactor at DC side, the peak value of capacitor discharge current decreases gradually, and the fluctuation of feed current at AC side decreases in steady state. This result is consistent with the analysis of current limiting principle of adding current limiting reactor at $\mathrm{DC}$ side.

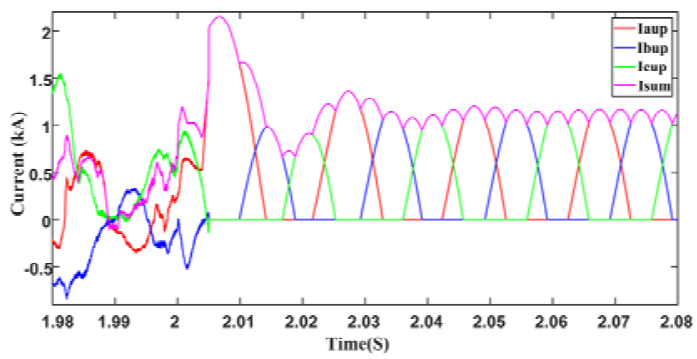

(a) $0 \mathrm{mH}$
The three-phase bridge arm current is shown in Figure 6 (a), (b), (c) respectively. Where, $I_{\text {aup }}, I_{b u p}$, $I_{\text {cup }}$ and $I_{\text {sum }}$ are the A-phase upper-arm current, the Bphase upper-arm current, the C-phase upper-arm current, and the sum of three-phase upper arm current.

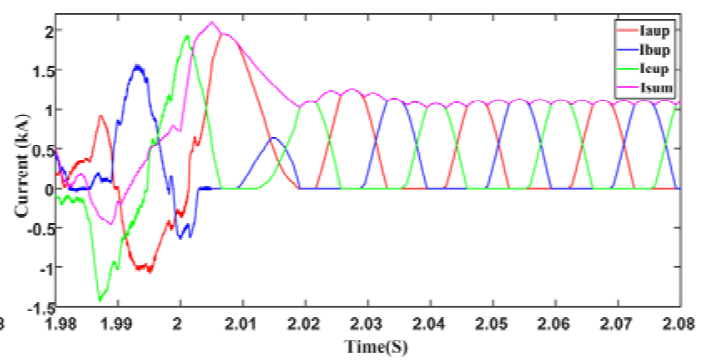

(b) $30 \mathrm{mH}$

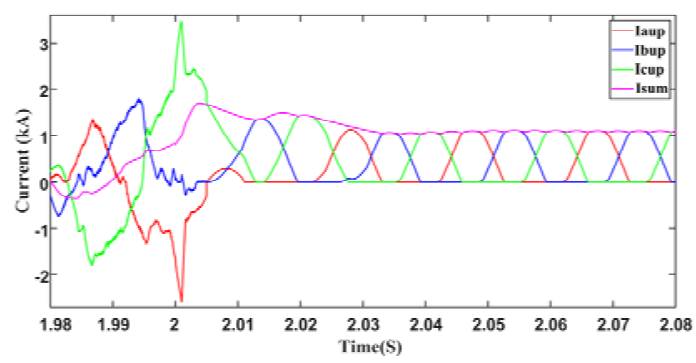

(c) $60 \mathrm{mH}$

Figure 6 Bridge arm current waveform when a current limiting reactor is installed on the DC side

It can be seen that installing a current-limiting reactor at the outlet of the DC side has no obvious effect on the amplitude of the bridge arm current in the steady state, but it can effectively slow down the peak of bridge arm current. Since the sum of three-phase bridge arm current is the DC side fault current, the fluctuation of DC side fault current is reduced. On the other hand, with the increase of reactor reactance, the fluctuation of DC side current and voltage will also rise during normal operation, so the DC side reactance can not be increased without limit.

\subsection{Simulation Analysis of Current Limiting Installation of Reactor on AC Side}

Install $0 \mathrm{mH}, 10 \mathrm{mH}$ and $20 \mathrm{mH}$ current-limiting reactors respectively at the outlet of the $\mathrm{AC}$ side. The current of the DC side line after the fault is shown in Figure 7. 


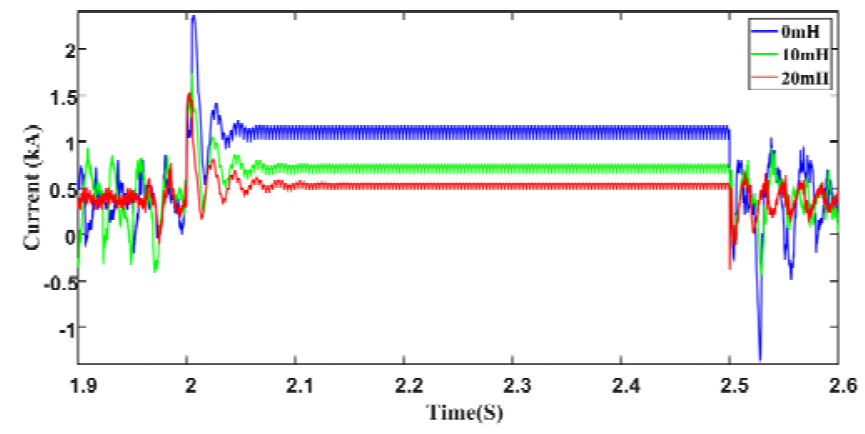

Figure 7 Fault current waveforms with current-limiting reactor at AC side

It can be seen that with the increase of reactance value of current limiting reactor at $\mathrm{AC}$ side, the overall amplitude of fault current decreases obviously, and the current fluctuation also decreases. This result is

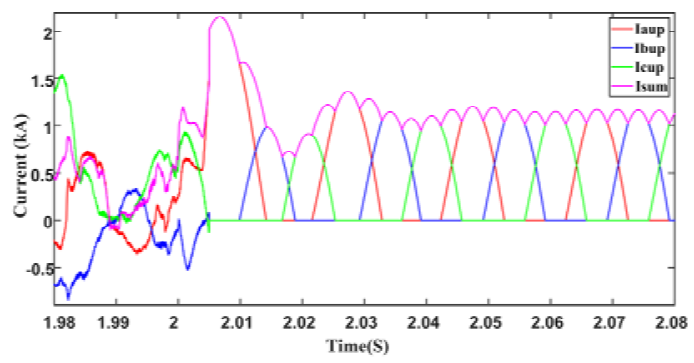

(a) $0 \mathrm{mH}$ consistent with the analysis of current limiting principle of adding current limiting reactor at $\mathrm{AC}$ side.

The three-phase bridge arm current is shown in Figure 8 (a), (b), (c) respectively.

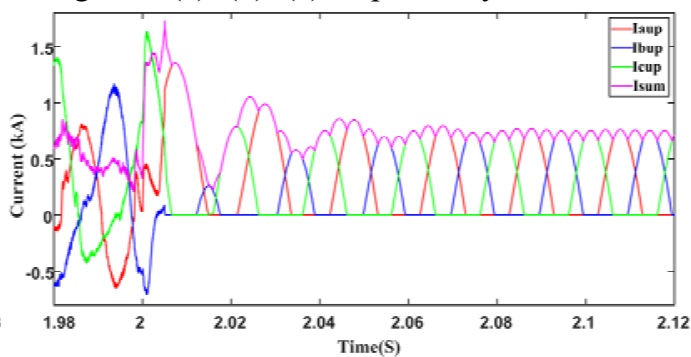

(b) $10 \mathrm{mH}$

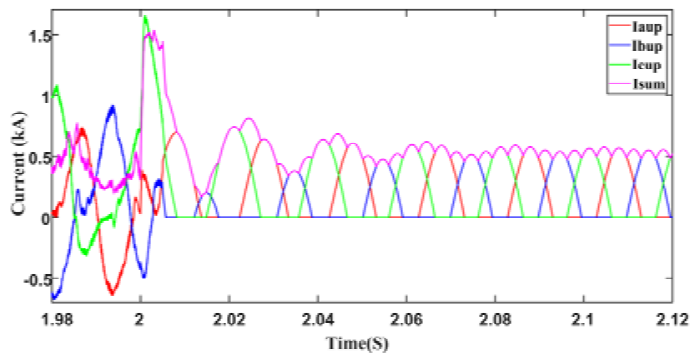

(c) $20 \mathrm{mH}$

Figure 8 Bridge arm current waveform when a current limiting reactor is installed on the AC side

It can be seen that adding a current limiting reactor at the outlet of the AC side can significantly reduce the current amplitude of the bridge arm, and the current fluctuation also decreases, which makes the DC side fault current significantly reduce, but has no obvious effect on the current fluctuation during the capacitor discharge stage. On the other hand, with the increase of reactance value of $\mathrm{AC}$ side reactor, the time for fault current to reach steady state after blocking also increases.

\section{Conclusion}

Aiming at the DC distribution system based on half bridge MMC, this paper analyses the fault mechanism and characteristics of pole-to-pole short circuit faults, studies the current-limiting effect of the reactor installation location and capacity on the fault current. The simulation verification is carried out in the PSCAD/EMTDC platform. The conclusions are as follows:
(1) Installing a current-limiting reactor at the outlet of the DC side can effectively reduce the peak value of capacitor discharge current, reduce the fluctuation of steady-state fault current, and has no obvious effect on the amplitude of steady-state fault current. With the increase of reactance value, the fluctuation of DC voltage and current will increase during normal operation.

(2) Installing a current-limiting reactor at the outlet of the AC side can effectively reduce the overall amplitude of fault current and the fluctuation of fault current in steady state, but it has no obvious effect on the current fluctuation of capacitor discharge stage. With the increase of reactance, the time for fault current to reach steady state after blocking increases.

\section{Acknowledgments}

This work was supported by National Key R\&D Program of China (2018YFB0904700).

This work was supported by the S\&T Program of Hebei (20312102D). 
This work was supported by the State Grid Corporation of China Science and Technology Project.

\section{References}

1. JIANG D, ZHENG H. Research status and developing prospect of DC distribution network [J]. Automation of Electric Power Systems, 2012,36(8):98-104.

2. SONG Q, ZHAO B, LIU W, et al. An overview of research on smart DC distribution power network [J]. Proceedings of the CSEE, 2013,33(25):9-19.

3. YANG H, WANG W, JING L, et al. Analysis on transient characteristic of DC transmission line fault in MMC based HVDC transmission System [J]. Power System Technology, 2016,40(01):40-46.

4. ZHANG G, QI X, CHEN Y, et al. Characteristic analysis of modular multilevel converter under DC pole-to-pole short-circuit fault [J]. Automation of Electric Power Systems, 2016,40(12):151-157.

5. LI B, HE J. DC fault analysis and current limiting technique for VSC-based DC distribution system [J]. Proceedings of the CSEE, 2015,35(12):3026-3036.

6. QIN H, SUN G SHI B, et al. Research on control and protection strategy of MMC based DC distribution grid with interpoles fault $[\mathrm{J}]$. Power System Protection and Control, 2016,44(21):150156.

7. LI B, LI Y, HE J. DC fault handling scheme for the MMC-based DC system [J]. Proceedings of the CSEE, 2016,36(07):1944-1950.

8. ZHANG F, XU J, YUAN B, et al. Over current suppression control for $\mathrm{AC}$ and $\mathrm{DC}$ faults of modular multilevel converters based on virtual impedance $[\mathrm{J}]$. Proceedings of the CSEE, 2016,36(08):2103-2113.

9. LI B, LI Y, HE J, et al. Stable fault characteristic analysis of the DC system based on modular multilevel converter [J]. Power System Protection and Control, 2016,44(21):1-8.

10. WANG S, ZHOU X, TANG G, et al. Analysis of submodule overcurrent caused by DC pole-to-pole fault in modular multilevel converter HVDC system [J]. Proceedings of the CSEE, 2011,31(01):1-7. 